\title{
Música para tus (jóvenes) oídos. Percepción, usos y costumbres de la audiencia universitaria de Gaztea Irratia
}

\author{
Musika zure belarrientzat (gazteak). Gaztea Irratia entzuten duten \\ unibertsitarioen pertzepzioa, erabilerak eta ohiturak. \\ Music for your (young) ears. Perception, practices \\ and customs of the university audience of Gaztea Irratia
}

\author{
Lola Costa Gálvez ${ }^{\star}$
}

Universitat de Girona (UdG)

RESUMEN: La radio musical pública juega un papel importante en la promoción de la industria, la cultura musical y el idioma de un territorio. Con este contexto, se plantea una investigación que incluye a la audiencia del sistema de medios públicos: la ciudadanía. Así, la pregunta de investigación es la siguiente: ¿cuál es la percepción ciudadana de la radio musical pública en Euskadi? Se plantea el caso de estudio de Gaztea Irratia, emisora musical de la corporación audiovisual pública EITB. La metodología cualitativa se compone de focus group con oyentes de la emisora seleccionados entre estudiantes universitarios de la UPV/EHU.

PALABRAS CLAVE: Radio; música; audiencia; jóvenes; EITB; servicio público.

ABSTRACT: Music radio has an important role in the promotion of the music industry, music culture and local language. Within this context, the research addresses the public media audience: citizenship. Therefore, the research question is the following: what is the public perception of public music radio in the Basque Country? Specifically, it presents the case study of Gaztea Irratia, a music station of the public audio-visual corporation EITB. Qualitative methodology is based on focus group with listeners selected among UPV/EHU university students.

KEYWORDS: Radio; music; audience; youth; EITB; public service media.

\footnotetext{
* Correspondencia a / Corresponding author: Lola Costa Gálvez. Universitat de Girona (UdG). Plaça Josep Ferrater i Móra, 1 (17004 Girona)-lola.costa@udg.edu - http://orcid.org/0000-0001-5003-5269

Cómo citar / How to cite: Costa Gálvez, Lola (2019). «Música para tus (jóvenes) oídos. Percepción, usos y costumbres de la audiencia universitaria de Gaztea Irratian; Zer, 24(46), 269-288. (https://doi.org/10.1387/zer.20629).

Recibido: 11 marzo, 2019; Aceptado: 29 abril, 2019.

ISSN 1137-1102 - eISSN 1989-631X / (c) 2019 UPV/EHU

(c) (i) Esta obra está bajo una licencia
} 


\section{Introducción}

El renacimiento de la música en euskera, en la misma línea que el catalán o el gallego, y aunque siempre había estado presente a nivel social, se puede situar a finales de los años 70 (del Amo, 2014; Martín Matos, 2013; Saudrigas, 2009). En aquellos momentos, la cultura vivía momentos de gran creatividad, a pesar de las reducidas posibilidades técnicas y de difusión. Fue entonces cuando se forjó un sistema público que actuó de soporte a las manifestaciones culturales del territorio y se convirtió en parte fundamental del mecanismo de las industrias culturales: los medios públicos. Así, a finales de los años 80 nacieron las primeras corporaciones audiovisuales en Euskadi y Catalunya que contribuyeron a acabar de conformar el mapa audiovisual vasco (Larondo Urreta, 2016) y catalán (Guimerà i Orts, 2014).

La música ha formado parte de las programaciones radiofónicas y televisivas desde sus inicios (Frith, 2002; Martínez-Costa y Moreno Moreno, 2004) y especialmente en el caso de la radio, siendo la música el germen de la especialización radiofónica (Pedrero Esteban, 2000). En el caso de los medios públicos han canalizado el patrimonio musical convirtiéndose en un verdadero motor de la industria y la escena musical, pero con notables diferencias entre la televisión (Hoyos, 2015) y la radio (Costa Gálvez, 2017). Estudios previos muestran como la radio musical ha sido pionera en el ámbito digital con propuestas innovadoras como iCat.cat (Bonet, Fernández-Quijada y Ribes, 2011), contenidos exclusivos por Internet (Bonet y Sellas, 2016) y, sobre todo, la capacidad de la radio de establecer relaciones permanentes con los oyentes (Wall y Dubber, 2009). Además, la radio musical pública ha desarrollado un modelo lingüístico basado en el entretenimiento, pero con un léxico «sin comillas ni barbarismos» (Gendrau, 2012: 179) que se ha revelado especialmente exitoso en la difusión y normalización del euskera entre la audiencia juvenil (Elordui, 2016; Landabidea Urresti, 2013).

En línea con los cambios acontecidos en el sistema comunicativo global (Miguel y Casado, 2016), en 2019 la música en euskera ha pasado de un ámbito local a la esfera global. La llegada de Internet ha nutrido el consumo cultural en todo el mundo, así mismo en el caso de la música (Min Baek, 2015) y muy especialmente entre los más jóvenes con la utilización de las redes sociales (Bonini, 2014). Sin duda la creación en euskera cuenta con la ventaja de no tener competencia, pero sin embargo dos impedimentos, que por otro lado son comunes a otras industrias culturales: una estructura sectorial frágil y los desequilibrios en los flujos culturales y comunicativos (Zallo, 2018a). Dentro de esta cultura musical destaca la asistencia a conciertos, según datos del Observatorio Vasco de la Juventud, un 38,6\% de los jóvenes entre 15 y 29 años asisten regularmente a conciertos, pero sin embargo solo un $11,8 \%$ de estos son en euskera (Gazte Aukera, 2017).

En su momento, la llegada de Internet fue definida como «el nuevo bautismo de la radio» (Peñafiel, 2007: 24). Desde entonces la innovación se ha desarrollado en el 
mercado radiofónico basada en el podcasting o el broadband. En este escenario de innovación tecnológica, la pérdida de audiencia joven es una de las principales preocupaciones tanto del sector radiofónico (BBC Trust, 2015) como de la academia (Gutiérrez, Ribes y Monclús, 2011; López Vidales, Gómez Rubio y Redondo García, 2014). En Euskadi, la radio musical es netamente juvenil, según datos del Observatorio Vasco de la Juventud, un 83\% de los jóvenes entre 15 y 29 años tienen preferencia por este tipo de radio frente al $42 \%$ de los mayores de 30 años (Gazte Aukera, 2013). Aún teniendo en cuenta las diversas franjas de edad que componen la llamada «audiencia juvenil» (EBU, 2014b) una cosa es clara: el consumo radiofónico en la franja de edad más joven está en crisis (EBU, 2018).

Dentro de este contexto digital, nos preguntamos cuál es la percepción que tienen los públicos, la ciudadanía, en definitiva, hacia los medios públicos en Euskadi. Específicamente nos acercamos a la radio, el medio más musical de todos, como el vehículo conductor de la cultura y a la vez garante por su función de servicio público de dos de los elementos preeminentes en cualquier cultura: la música y la lengua. Es precisamente una visión global de los medios audiovisuales, lo que mueve nuestro objetivo general: ¿̨cuál es la percepción ciudadana de la radio musical pública en Euskadi? EITB cuenta con dos emisoras musicales: Gaztea Irratia y EITB Musika. Gaztea Irratia $^{1}$ es la que más tiempo lleva en activo y la que mejores resultados de audiencia obtiene, 113.000 oyentes Gaztea y 38.000 EITB Musika (EITB, 2018). Además, las dos emisoras están perfectamente diferenciadas a nivel de audiencia: EITB Musika está «dirigida al público adulto» y Gaztea «al público joven» (EITB, 2013b), de hecho, el director de Gaztea señala a la audiencia entre 15 y 30 años como el público prioritario (Lamarca, 2018). Además, aunque las dos emisoras se basan en la radiofórmula, según el modelo programático de Martí (1990); Gaztea es la que tiene un mayor número de programas (12) y EITB Musika tan solo tres.

La investigación tiene como base la revisión del concepto de Public Value Test (PVT) como instrumento de medida de la relación de los medios públicos con la ciudadanía (Comisión Europea, 2009). Como contexto pondremos los datos de la edición especial del Sociómetro Vasco dedicado a EITB, en el cual Gaztea Irratia tuvo una valoración de 7,9 en la pregunta de promoción del euskera (Eusko Jauralitza, 2018). En definitiva, se hará un recorrido sobre la definición del modelo de Gaztea Irratia desde la perspectiva del servicio público, y dentro de un ecosistema cultural industrial como es el de la música y la radio, para llegar a la traducción de estas funciones en programaciones y estrategias digitales que finalmente llegan a sus destinatarios: los oyentes.

\footnotetext{
1 En adelante nos referiremos a Gaztea Irratia como Gaztea.
} 


\section{Metodología}

El presente artículo es parte del proyecto de investigación titulado «Música, lengua y servicio público: evaluación de la percepción ciudadana de la radio musical pública en Catalunya (CCMA) y Euskadi (EITB)» financiado por la 21a Convocatoria de Bolsas de Estudio Eusko-Ikaskuntza-Institut d'Estudis Catalans ${ }^{2}$. Los datos que se presentan fueron recabados durante una estancia de investigación en el Departamento de Comunicación Audiovisual y Publicidad de la Universidad del País Vasco/Euskal Herriko Unibertsitatea (UPV/EHU) durante los meses de septiembre a noviembre de 2018. Esta estancia ha resultado provechosa para la captación de participantes del focus group y la realización de entrevistas ${ }^{3}$.

El focus group es una técnica de investigación cualitativa que permite conocer en profundidad una realidad social. Específicamente queremos responder a los siguientes objetivos:

- Conocer la cotidianeidad del consumo radiofónico.

- Conocer los hábitos de consumo musical.

- Conocer la dieta mediática.

- Conocer los atributos que los oyentes dan a Gaztea Irratia.

- Conocer la opinión de los oyentes respecto a los contenidos de Gaztea Irratia.

- Conocer la opinión de los oyentes respecto a la utilización del euskera en Gaztea Irratia.

- Conocer la actitud e interacción de los oyentes respecto a Gaztea Irratia.

Para la realización de los focus group se ha escogido la franja de edad entre 18 y 25 años. Como se ha expuesto, es una horquilla prioritaria para los radiodifusores, pero también es la base de los oyentes de Gaztea. De este modo, los participantes han sido captados en la Facultad de Ciencias Sociales y de la Comunicación de la Universidad del País Vasco/Euskal Herriko Unibertsitatea (UPV/EHU). La elección de este centro obedece a dos motivos. Por un lado, resultaba asequible para la investigadora ya que el procedimiento de captación de participantes es intensivo y tedioso. Por otro lado, era bastante probable encontrar individuos con unas caracte-

\footnotetext{
2 https://www.iec.cat/institucio/documents/PremisSantJordi2018.pdf

3 Esta estancia también ha sido enriquecedora para el diálogo académico, tan necesario en tiempos de individualismo. Por ello, quiero agradecer a todos los miembros, dirección y personal del departamento que hicieron tan agradable mi estancia y me ayudaron a lograr mis propósitos. Especialmente a Estefanía Jiménez, Miguel Ángel Casado, Juan Carlos Miguel, Carmelo Garitaonandia, Sergio Monge, Gotzon Toral o Asier Arrieta. También a miembros de otros departamentos como Carmen Peñafiel, Joseba Martín, Andrés Dávila, Agurtzane Elordui o Matxalen Legarreta. Por supuesto, a Ramón Zallo por su imprescindible entrevista.
} 
rísticas y estilo de vida compartidos, pero con orígenes muy diversos. Así, tenemos un universo de 2.340 alumnos matriculados (Euskampus, 2014). Finalmente, y tras varios intentos, se realizaron tres focus group que se describen en la siguiente tabla ${ }^{4}$ :

\section{TABLA 1}

Descripción de los focus group realizados ${ }^{5}$

\begin{tabular}{|c|c|c|c|}
\hline Fecha & Duración & Código & as \\
\hline $16 / 10 / 2018$ & 01:18:44 & G.I & $\begin{array}{l}\text { Grupo mixto (siete personas) de alumnos de segundo curso del } \\
\text { Grado en Comunicación Audiovisual de la UPV/EHU (Leioa, } \\
\text { Bizkaia). } \\
\text { Cursan el itinerario euskera. } \\
\text { 18-20 años. } \\
\text { Nacidos en las provincias de Bizkaia (3) y Gipuzkoa (2) y la C.A. } \\
\text { de Nafarroa (2). } \\
\text { Lengua materna: castellano (5) y euskera (2) }\end{array}$ \\
\hline $24 / 10 / 2018$ & 49:12 & G.II & $\begin{array}{l}\text { Grupo mixto (seis personas) de alumnos de segundo curso del } \\
\text { Grado en Sociología de la UPV/EHU (Leioa, Bizkaia). } \\
\text { Cursan el itinerario castellano. } \\
\text { 19-20 años. } \\
\text { Nacidos en las provincias de Gipuzkoa (1), Araba (2), Bizkaia (2) } \\
\text { y la C.A. de Nafarroa (1). } \\
\text { Lengua materna: castellano (5) y euskera (1). }\end{array}$ \\
\hline $31 / 10 / 2018$ & 41:38 & G.III & $\begin{array}{l}\text { Grupo mixto (6 personas) de alumnos de segundo curso del } \\
\text { Grado en Comunicación Audiovisual, primer curso del Grado en } \\
\text { Periodismo y cuarto curso del Grado en Publicidad y Relaciones } \\
\text { Públicas de la UPV/EHU (Leioa, Bizkaia). } \\
\text { Cursan el itinerario euskera. } \\
\text { 18-22 años. } \\
\text { Nacidos en las provincias de Araba (2), Bizkaia (4) y la C.A. de } \\
\text { Nafarroa (1). } \\
\text { Lengua materna: castellano (2) y euskera (4). }\end{array}$ \\
\hline
\end{tabular}

Fuente: elaboración propia.

4 Para plantear y analizar los datos ha sido muy útil la tesis doctoral y los consejos de Estefanía Jiménez (2010).

5 Todos los participantes firmaron hoja de consentimiento para garantizar la confidencialidad de sus datos. 
Además, el trabajo se complementará con las entrevistas al director de Gaztea, Jon Lamarca, al catedrático de comunicación audiovisual y publicidad Ramón Zallo y a representantes de la industria musical en Euskadi, escogidos entre los miembros de MIE (Musika Industriaren Elkartea), el portal de la música vasca Badok, el catálogo discográfico del archivo de la música vasca Eresbil y el directorio de cultura del Gobierno Vasco, Kulturklik. En concreto Sarbide Music, Sonora Estudios y Erraia Diskoak. ${ }^{6}$

\section{Radio musical, Internet y audiencia juvenil: ¿hay alguien ahí?}

«Radio as a media form will always have a special role to play, whether it is analogue or digital» (EBU, 2014a: 4). Esta afirmación sirve para contextualizar una idea: la adaptación de la radio a cualquier escenario tecnológico. La «cultura de la portabilidad» (Herschmann y Kischinhevsky, 2008) ya está plenamente instaurada en los usuarios. En Europa el consumo de radio pública por parte de la audiencia joven es de 1 hora y 27 minutos diarios llegando tan solo al 22\% de cuota de mercado (EBU, 2018). En España un 26,4\% de los encuestados señalan escuchar la radio por Internet, mientras que el 20,3\% consume podcasts (AIMC 2019).

Una cuestión interesante es saber por qué escuchan la radio los participantes. La mayoría señalan a la tradición familiar como el germen de su interés por la radio. Muchos recuerdan tener la radio «de fondo" mientras sus padres o abuelos cocinaban, limpiaban, otros se acuerdan de escuchar la radio a la salida del partido de San Mamés y para otros el interés personal por la radio se despertó al ingresar en la universidad. Dentro de este contexto, algunos eligen la radio por razones «prácticas»: "Muchas veces escucho la radio porque no me queda otra, como cuando voy en el coche» (Unai, G.III) ${ }^{7}$. Para otros su primer encuentro con la radio fue fruto de la serendipia: «Para mí el interés por la radio fue fortuito. Me compré un radiocasete para escuchar música de un pen drive. Se me rompió y acabé escuchando el transistor» (Begoña, G.II). Para una participante, el aprendizaje del euskera la llevo a escuchar Gaztea, «me di cuenta de que servía mucho para aprender el idioma»(Udane, G.III). Para otro participante, sus motivaciones para escuchar la radio son más "poéticas»: "En la radio me obligo a imaginar, por eso me gusta» (Ibon, G.II).

\footnotetext{
${ }^{6}$ El proceso de obtención de entrevistas ha sido como era de esperar, complicado. Así, de los 45 emails enviados, tan solo se registraron cinco respuestas positivas de las que finalmente se realizaron tres entrevistas. Destacamos la respuesta afirmativa de MIE (Musika Industriaren Elkartea) que finalmente no se ha incluido por la negativa a firmar la hoja de consentimiento.

7 Los nombres de los participantes del focus group son ficticios.
} 
En cuanto a los hábitos, escuchar la radio mientras viajan es la actividad que más realizan los participantes del focus group. El consumo doméstico de la radio se produce mientras realizan alguna otra tarea como ducharse o limpiar e incluso como despertador. Ligado a estas acciones está la utilización de la FM para escuchar la emisión de flujo de la radio e Internet para escuchar música: «Si no tengo Internet en el móvil y no puedo escuchar Spotify, entonces pongo la radio, pero para escuchar emisoras musicales» (Ibai, G.I).

El podcast es el preferido cuando se trata de dedicar una escucha atenta a la radio. "Yo tengo una pregunta: ¿los programas de radio en YouTube son radio? Porque programas como La Vida Moderna los consumo diariamente» (Julen, G.I.). Esta idea la comparten varios de los participantes en distintos focus group. De hecho, Internet es el medio de comunicación que más consumen, y la prensa el que menos, todo ello directamente ligado con la idea del «bajo demanda":

Estamos un poco «maleducados» en la cultura de «a la carta». Consumo muchas películas, series, podcasts y música, pero no tengo la costumbre de 'voy a poner la radio a ver qué hay, no, pongo la radio para escuchar qué dice un programa muy concreto (Gorka, G.I).

La innovación tecnológica se ha incorporado plenamente a las estrategias de los medios públicos, especialmente para lograr el engagement con la ciudadanía (Hoyos y Costa Gálvez, 2017; Vangaeght y Donders, 2017). «Los servicios públicos no tienen que acantonarse en lo analógico, sino que tienen que estar presentes en todos aquellos lugares donde esté la audiencia, y eso incluye lo digital» (Zallo, 2018b). La página web de Gaztea constituye un elemento fundamental de la definición de la estrategia digital y así contiene bastante información adicional a la emisión. Encontramos un apartado específico para los videoclips («Bideoklipak») y para la promoción de los nuevos artistas está presente en los concursos «Talentu Gaztea» y «Maketa Lehiaketa». La publicación de los listados de reproducción también es importante para la emisora, así los programas B Aldea y Top Dance tienen un listado de reproducción que se puede escuchar con los temas que suenan. Además, se publican seis playlists en la página web de la emisora entre novedades musicales, artistas noveles y recopilatorios («100\% Gaztea», "Gaztea go», «Maketa lehiaketako taldeak», «Nobedadeak», «Top Gaztea» y «Top Dance»). Por otro lado, la estrategia en redes sociales se deja para los programas con mayor duración «Dida», «B Aldea» $\mathrm{y}$ «Gaztea Box»).

Garitaonandia (1988) se refería a la participación del oyente en los programas musicales de los primeros años de la radio en España como un caso único de interacción entre emisor y receptor. A este papel de la radio como «mediador» (Hennion y Meadel, 1986 298) se une el de los oyentes que "pueden aportar información en calidad de expertos y en virtud de su conocimiento profesional de la disciplina a la que se aluda» (Herrera Damas, 2003: 149). Encontramos ejemplos de 
participación del oyente son «La Tweetliste», en la cadena francesa Le Mouv', en el que los oyentes seleccionan los temas de la lista de éxitos a través de Twitter, o el «Playlister» de la BBC en el que los oyentes añaden contenido a sus listas de canciones, en el programa "Cuenta atrás», tiene el \#N1CanalFiesta en Twitter para votar por la canción o artista favorito o en Gaztea con el grupo de WhatsApp de «Dida».

La mayoría de los participantes en los focus group no interactúa con Gaztea. Algunos señalan haber utilizado el WhatsApp para pedir canciones, otros han participado en algún concurso, otros han visto algún directo de Instagram «pero solo por curiosidad» (Miren, G.I). Otros sí tienen una valoración positiva: «En Gaztea puedes pedir canciones y tienen en cuenta lo que quieren los oyentes» (Ainara, G.II). Incluso algunos de ellos rechazan la llamada a participación porque la consideran un recurso «fácil» para llenar contenido por parte de la emisora:

No estás interactuando con la radio, la radio suele ser un acompañamiento. Por eso muchas veces no tiene sentido llamar tanto a la participación del oyente. Lo interesante de la radio es descubrir lo que ponen y no poder interaccionar. Podría ser hasta contraproducente, porque para pedir y para exigir ya tienes otras fuentes como Spotify. (Markel, G.II)

\section{Música, euskera y juventud: win-win situation}

La capacidad de difusión que Internet da al producto musical provoca que el consumidor tenga más música que nunca a su disposición y de una manera más especializada, configurando lo que Bull (2005: 353) denomina "personalized soundworlds». El crecimiento mundial de los servicios de música en streaming ha sido exponencial. En 2003 eran menos de 50, en 2009 eran más de 300 y la cifra sigue creciendo hasta los 400 en 2015 (IFPI, 2015). En este contexto, la portabilidad y personalización de la música en Internet es un punto de partida fundamental para entender las motivaciones de la audiencia juvenil (Jauert, 2012).

En la era del "Music for everyone», como reclama el eslogan de Spotify la prescripción y los listados de reproducción (Costa Gálvez, 2013) son los puntos fuertes de la radio musical, definidos por Barnard (1989: 113) como los «keepers of the castle». Como señalan Gandarias y Cardiel (2018), de Sarbide Music: «la radio va a seguir haciendo falta para la promoción, sea masiva o no, así tendremos radios más mayoritarias y más «nichificadas», con toda la experiencia que tienen las radios debería ser fácil para ellos adaptarse al entorno digital». Sin duda el auge de los servicios de música en streaming y de plataformas como YouTube es visto como una de las principales amenazas a la radio musical (Aguiar y Martens, 2013). En 2015 el 94\% de los jóvenes entre 15 y 24 años son usuarios de Spotify (TNS y Spotify, 2015). La relevancia social de la radio, tanto la pública como la privada, ha mantenido y man- 
tiene al medio vivo (Barnett, 2004). «Las colaboraciones van surgiendo, pero estamos dentro de una estructura muy pesada como es EITB, lo que dificulta que podamos colaborar con youtubers o influencers» (Lamarca, 2018).

Aunque la radio musical es la que más escuchan, los participantes consumen mucha radio generalista: "Yo suelo escuchar más la radio musical, pero me entretiene más la generalista, dicen cosas más interesantes» (Miren, G.I). Para otros, el estado de ánimo es lo que determina sintonizar una emisora u otra: «Va a días. Hay días que te apetece escuchar lo que ya conoces y hay veces que te interesa descubrir cosas nuevas» (Nerea, G.I). Además, al mismo tiempo que le gusta destacan la "comercialidad» de las emisoras es el aspecto que más critican de la radio musical, otorgando un papel «neutral» a Internet:

Yo para descubrir música no acudo a la radio. Si un locutor te recomienda algo es porque alguien le están pagando de alguna manera. Prefiero la interacción entre usuarios que hay en un foro o en páginas webs, me fio más de estas recomendaciones. (Gaizka, G.I)

Internet es determinante en la popularización de los contenidos musicales, tanto para usuarios como productores. Especialmente en la distribución, parte primordial de la cadena de valor del producto musical, que se ha desplazado de los soportes físicos hacia un consumo fraccionado en el mercado online muy relacionado con la música en streaming (Nylund Hagen, 2015). YouTube y Spotify son los canales más señalados para escuchar música por los participantes, incluso se decantan por YouTube "porque mucha música de la que escucho no la encuentro en Spotify» (Gaizka, G.I). Algunos se declaran claramente analógicos: «Yo mantengo la tradición de 1.200 canciones en el móvil» (Unax, G.I).

«Gaztea es una emisora que va con la música en euskera, no con la industria de la música en euskera. Músicos sin sello, muy difícil que vayan a sonar, por razones de profesionalidad y de audiencia» (Lamarca, 2018). MIE (Musika Industriaren Elkartea) es la asociación de editores musicales, cuenta con 47 empresas dedicadas a diversas partes de la edición fonográfica. Es una de las asociaciones relacionadas con la música que reciben subvención del Gobierno Vasco junto con Eresbil, el archivo vasco de la música, la Joven Orquesta de Euskal Herria y la Orquesta Sinfónica de Euskadi. «Hay un cierto tejido industrial, lo que ha caído es la edición fonográfica pero la música en vivo se mantiene. Además, hay un interés por parte de las autoridades, que no es que sean amantes de la música, sino que les sirve para 'hacer país', buscan un efecto Guggenheim» (Zallo, 2018b). Según datos del Departamento de Cultura y Política Lingüística (2019), en 2018 las subvenciones para la creación musical fueron de $50.000 €$ y las de actividades musicales se dividieron en $30.000 €$ para la edición de partituras, 155.000€ para proyectos musicales, 205.000€ para iniciativas musicales empresariales y $140.000 €$ para programación musical. 
Pero ¿qué música escuchan los participantes de los focus group? Podríamos definir su consumo musical en base al género, el idioma y la asistencia a conciertos. Todos señalan escuchar "de todo» y tener una «actitud abierta» ante la música. Sin embargo, cuando la moderadora les pregunta si dentro de este todo escuchan, por ejemplo, ópera, responden al unísono que «ino!». Todos señalan que la música forma parte de sus maneras de vivir: "Yo hasta para atarme los zapatos me pongo música» (Unax, G.I). Gran parte de ellos señalan a la autenticidad y lo underground como fuentes de inspiración principales: "Yo escucho de todo y dentro de ese todo, lo más raro». (Patxi, G.I). Esa dicotomía de «industrializado, malo; independiente, bueno» que señalaba Negus (2005) lo que denominó «las multinacionales del género», es una idea que comparten buena parte de los participantes:

Yo siempre he unido el consumo de música a la tendencia popular. Si en los 60 eran los Beatles, hoy en día es C.Tangana» (Gaizka, G.I). «Mucha música que ahora es popular era underground. En cuando se institucionaliza y lo cogen las discográficas, pierde su esencia. (Markel, G.II)

Según datos del Instituto Vasco de Estadística, un 36,44\% de la población de Euskadi es bilingüe castellano-euskera (EUSTAT, 2011). Un 69,3\% de los jóvenes utiliza el euskera como lengua vehicular y un $38,1 \%$ lo utiliza como lengua de comunicación con su entorno (Gazte Aukera, 2017). Todos señalan escuchar música en euskera «desde siempre». De hecho, una buena parte de ellos tienen una opinión muy positiva al respecto: "A mí me hace hasta ilusión que haya música en euskera. Incluso hasta por una razón política» (Igor, G.II). Además, gran parte de los participantes no tienen como lengua materna el euskera y consideran que la música es una forma de transmisión del idioma. La mayoría coinciden en que están muy «expuestos» a la música en euskera "aunque no lo hables, la música te llega: en las fiestas, en la ikastola, en la radio» (Miren, G.I). Muchos aluden a «el peso de la historia», en palabras de muchos de ellos, del rock radikal vasco en su gusto por la música en euskera. De hecho, ante la pregunta "¿Y cómo sentís esto, cercano o alejado?» «Cercano», responden al unísono. Sin embargo, aunque la mayoría se sienten cercanos, no siempre consumen música en euskera: «Es la música de mi entorno, pero no afecta a mi gusto. Porque una música sea en euskera no la voy a escoger. Lo que importa es que me guste o no» (Ibai, G.I). Martín Guridi (2018), de Sonora Estudios, puntualiza al respecto: "Hay mucha insistencia por parte de las administraciones públicas en que haya cuanta más cantidad pues mejor de músicos que canten en euskera, pero porque presentes una canción en euskera a un concurso no eres un músico que cante en euskera».

Prácticamente todos asisten habitualmente a conciertos. Muchos señalan que en Bilbao hay oferta de muchos géneros y estilos, factor que cambia cuando se mueven a ambientes rurales. Sin embargo, el factor local es importante: «la mayoría de oferta es de aquí y yo en parte lo agradezco» (Igor, G.II). El factor económico es clave en 
la decisión de ir a un concierto y aquí entra en juego el idioma: la música en euskera suele ser gratis. Así, gran parte de ellos van a conciertos de gaztetxes y en fiestas populares. De hecho, muchos han descubierto música en euskera por los conciertos: «Yo en mi adolescencia nunca escuchaba música en euskera. Cuando empecé a ir a las fiestas de los pueblos, empecé a escuchar música en euskera» (Nahia, G.III). Otros simplemente señalan que el ambiente festivo en el que asisten a conciertos condiciona su comportamiento: "Yo a veces voy porque me interesa el grupo y otras veces voy por la fiesta, entonces a veces te quedas 'litrando' y al final no ves el concierto» (Imanol, G.III).

\section{Radio musical y servicio público en Euskadi: gaztea significa algo más que «joven»}

Creada en 1990, Gaztea es la emisora juvenil en euskera por excelencia del grupo EITB y de hecho es definida como «radio fórmula juvenil» en muchos documentos legales y corporativos (Departamento de Presidencia, Consejería de Hacienda y Administración Pública, Consejería de Cultura, EITB, 2007; Consejería de Cultura, EITB, 2012; EITB, 2012d). El entretenimiento «propio del segmento más joven» (EITB, 2013b) es otro de los rasgos definitorios de la emisora. En 2005, hubo un cambio de orientación de Gaztea, justamente coincidiendo con el nacimiento de EITB Musika. De este modo, aumentan las alusiones al «entretenimiento» (EITB, 2013a), establecido como un objetivo prioritario en el plan estratégico de EITB para 2013-2016 y relacionado con el «segmento más joven» (EITB, 2013b: 22). Como comenta Zallo (2018b):

Gaztea y EITB Musika tienen un compromiso con la música de Euskadi, no con la industria musical de Euskadi. Este compromiso no existe en ETB, donde la música siempre queda relegada a la última noticia del Teleberri, hay una especie de «agujero negro». ${ }^{8}$

«Una de las condiciones fundamentales de una emisora pública es que tenga público", comentaba el director de Gaztea, Jon Lamarca (2018). La mayoría de participantes destacan el éxito social de Gaztea: «En nuestro entorno funciona, escuchan Gaztea las 24 horas. Las demás cosas no les interesan» (Ibai, G.I) o «al final las radios por Internet que ponen música de calidad y emiten en euskera no son tan conocidas y Gaztea juega con la ventaja de la popularidad» (Julen, G.I).

\footnotetext{
${ }^{8}$ No es objeto de este artículo, pero no podemos pasar por alto la compleja situación laboral de muchos trabajadores de EITB y por ende también de Gaztea, un aspecto comentado por los dos entrevistados (Lamarca, 2018; Zallo, 2018b).
} 
¿Cómo debe ser una radio musical de servicio público? Es esta una pregunta que podríamos responder con otra cuestión, ¿qué se debe programar en una radio musical de servicio público? Señala Blumler (2014) el rol central que juega la programación en la concepción de los servicios públicos:

It seems to me that there has been some sort of reductions of the public service idea to rather general notions like programme quality, range of programming. There is a sort of programming definitions that can include almost all kind of programmes. There has been a change into the search for the audience, of course it should be, a public service broadcaster has to have public, but there has been an 'involution' to the citizen consumer to the consumer citizen.

«El tema aquí es: cómo hace Gaztea algo distinto pero que sea parecido a lo que les gusta a los jóvenes» (Zallo, 2018b). En un contexto digital, cobra relevancia "el contenido». Ante la ausencia de cuotas de música en euskera en los medios de comunicación de Euskadi se recogen algunas ideas que perfilan la programación de la radio musical pública vasca. Así, en el segundo contrato programa suscrito se citan cuatro objetivos relacionados con la programación cultural, entre los que se incluyen aumentar el porcentaje de los programas dedicados a la cultura y su evaluación (Departamento de Presidencia, Consejería de Hacienda y Administración Pública, Consejería de Cultura, EITB, 2007). Por otro lado, el balance del contrato programa de EITB, 2002-2005 especifica que la radio deberá "promocionar la difusión y el conocimiento de la música en sus distintos géneros» (Departamento de Cultura del Gobierno Vasco, 2006: 38). En definitiva, como comenta Zallo (2018b): "Que el gusto por la música sea transnacional no es malo, significa que has accedido a ese segmento, pero eso no quita que no debas dejar de cultivar tu cultura».

«Mucha gente aprecia Gaztea porque solo emiten en euskera. En muchos entornos no está normalizado hablar castellano y esto es un punto a favor. A la gente no le apetece escuchar radio en castellano» (Julen, G.I). El euskera y el tono juvenil es lo que los participantes creen que diferencia más a Gaztea de otras emisoras: «Si te pones ese nombre, pues qué más quieres, tienes que emitir en euskera. Me parece importante que al menos una radio mantenga la emisión en euskera» (Julen, G.I).

Consideran al euskera un idioma «rico» por la cantidad de variedades dialectales y esta es la principal razón por la que ven difícil emitir fuera del estándar. La mayoría consideran que la «base» de la emisión es el batua: «A mí me parece bien que metan muchas formas de hablar. Al final que Jon Gotzon hable en euskañol hace que los oyentes se sientan más cercanos» (Nekane, G.III). Entre los que no tienen el euskera como lengua materna destacan las opiniones a favor de emitir en las variedades dialectales, "para aprender, para escuchar otras cosas que no conozco» (Begoña, G.II). 
Sin embargo, a algunos les resulta extraña esta práctica: "Quieren hacer batua para que lo entienda todo el mundo, pero para que no quede "forzado" meten euskalki y queda raro» (Ibai, G.I).

La programación de Gaztea sigue la estructura de radiofórmula. Así, tenemos un programa despertador («Dida»), un magazín de tardes ("Gaztea Box») y un programa especializado en franja nocturna («B Aldea»). De los tres programas citados «B Aldea» es el que más música en euskera programa, «hay muchos músicos que dicen «B Aldea bai, Gaztea ez» (Lamarca, 2018). Los sábados se emite en horario de 12 a 14 horas «Top Gaztea», un programa al estilo Top 40 pero en formato reducido. La oferta los fines de semana se complementa con sesiones de DJ's («Las Tea Party», «Mync», «Akabo Bakea!»), una estrategia que la emisora ha ido incrementando en los últimos años. En línea con la estrategia de otras emisoras, tienen material elaborado exclusivamente para la página web ya que «Top Dance» no se emite, sino que es una lista de reproducción que se elabora desde la emisora.

«No podemos renegar del pasado del rock radikal vasco pero Gaztea es una emisora 100\% comercial que presta atención a los márgenes» (Lamarca, 2018). La mayoría de los participantes aprecian que el contenido musical de Gaztea tiene tendencia hacia la comercialidad: "Al final van a lo que van todos: a pillar oyentes» (Udane, G.III) o "Si algo está muy de moda, van a poner eso casi seguro» (Ibai, G.I) De hecho, la selección musical determina en cierta medida que los participantes escuchen Gaztea principalmente por la mañana o por la tarde: "Yo he notado que por la tarde la música es demasiado repetitiva, como que esperan que la mayoría de audiencia esté en esa franja» (Miren, G.I).

¿Qué tipo de música creéis que se pone en Gaztea? Las respuestas orbitan entre «música comercial»y «música local». Ponen ejemplos como el de Aneguria, que según muchos ha saltado a la fama por Gaztea. A algunos sí les parece que descubren música que es de su interés: «Si tengo que escoger pongo Gaztea porque: 1) ponen música en euskera y 2) a veces descubro cosas nuevas» (Miren, G.I).

La mayoría creen que las canciones que suenan en Gaztea se seleccionan por un criterio de éxito. Algunos sugieren que miran el top 10 de más escuchadas en Spotify o en emisoras anglosajonas «y encima las ponen con bastante tiempo de retraso» (Maite, G.III). Tampoco creen que la música que suena en Gaztea sea diferente de la que suena a nivel nacional o internacional: «En comparación con el mundo anglosajón no ponen nada nuevo, pero yo creo que tampoco les interesa eso» (Ekaitz, G.III). Respecto a la música en euskera, consideran que solo suenan los singles de cada grupo: "Casi siempre que la escucho están hablando de algún "top"» (Julen, G.I). La percepción es que por la noche suenan canciones más desconocidas, por razones de audiencia: «Ponen lo que le gusta a la juventud, básicamente» (Ibai, G.I). 
La música en euskera es otra de las bazas de Gaztea. Los participantes consideran que la emisora está en línea con «lo que está de moda": «Siguen una dinámica en la que, si hay un estilo que se pone de moda, como por ejemplo el trap, pues acumulan a un montón de gente que va del mismo palo y ya saben que van a tener éxito» (Igor, G.II). En la promoción de la música en euskera juega un papel importante concursos como «Maketa Lehiaketa» o «DJ Lehiaketa» son parte del contenido de la emisora. Una dinámica que, como explica su director, también tiene su estrategia: «no hacemos apuestas por un caballo perdedor, escogemos artistas que tendrán un cierto recorrido en la emisora» (Lamarca, 2018). Esta es una idea que manifiestan muchos participantes: «Muchos son productos prefabricados, es lo mismo de siempre, lo comercial. Hacen concursos para descubrir talentos, pero al final son artistas a media asta, gente que ya saben cómo va a acabar» (Begoña, G.II).

Señala el director de Gaztea que una de las vías de futuro de la radio es la organización de eventos (Lamarca, 2018). Los participantes en general no asisten ni están al día de los eventos organizados por la emisora. Sobre todo, destacan que solo asistirían a esos eventos si fueran gratuitos: "Yo fui a un evento de Gaztea por casualidad y me gustó. Descubrí grupos nuevos» (Ibai, G.I).

Llegados a este punto del texto podemos formular una pregunta que a modo de resumen aporta también contenido nuevo: ¿cómo debe ser Gaztea desde la perspectiva del servicio público? La mayoría de los participantes valoran la existencia de medios públicos, aunque con una consideración similar a la de los libres o alternativos: "Si analizo bien la situación y hago una crítica tengo claro que una radio pública debe ofrecer servicio público» (Gorka, G.II). En el caso de Gaztea, las opiniones se dividen entre la viabilidad económica al mix entre contenidos comerciales y de calidad: «Me parecerá mejor o peor, pero hay que mantener un presupuesto. Tienen que poner lo que a la gente le gusta escuchar» (Miren, G.I) o «No creo que sea incompatible lo comercial con lo alternativo" (Iker, G.II).

Restar el poso de comercialidad de Gaztea, «poner algo que no sea lo comercial de siempre» (Begoña, G.II) es una de las primeras ideas que dan los participantes, aunque valorando el contexto en el que están: «Mi primera idea sería quitar la música comercial y la música de fuera, aún sabiendo que esto le atrae al público, aunque lo que hacen ahora seguro que también le quita público» (Ibai, G.I). De hecho, tienen claro que "hacer una radio menos comercial significaría restar audiencia a Gaztea» (Julen, G.I). Incluso algunos proponen soluciones: «Una solución podría ser que la radio convencional fuera más comercial y luego en Internet poner música menos conocida.» (Ibai, G.I). En este sentido señala Jon Aramburu (2018), de Erraia Diskoak: «a los medios de comunicación solo les interesa la novedad, seguramente cuando hagamos un lanzamiento tengamos posibilidades de salir en Gaztea, han hablado de nosotros en algún programa especializado, pero no en toda su programación». 
Otro punto fundamental es que consideran que la radio pública debe apoyar a los artistas emergentes, «a los que tienen menos oportunidades» (Begoña, G.II). En este sentido, dar un espacio a la música local también se considera importante, aunque no prioritario. En definitiva, subyace la idea de que «más que a lo local yo prestaría atención a lo que no tiene repercusión a nivel internacional» (Telmo, G.II).

La mayoría mantendrían la emisión en las variedades dialectales del euskera, pero cambiarían el tono de la locución: "A mí no me atrae demasiado el tono, es demasiado forzado, es un tono como de presentador de la EITB» (Julen, G.I). Otro señala que «me gustaría que tuvieran un tono más como de presentador de Radio 3» (Ibai, G.I).

Como exponía Jakubowicz (2007), «¿quién si no nosotros?». Esta idea subyace en muchas opiniones de los participantes:

Yo creo que, si el Estado financia algo, la mínima preocupación debe de ser la rentabilidad. Es igual para un medio de comunicación que para la sanidad. (Gaizka, G.I)

La base es qué consideramos como "público», a quién están supeditados. Hay muchas cosas, como la música en euskera, al final dónde va a ser. (Aitor, G.II)

Como no concluir esta sección, con la respuesta de Ramón Zallo a la pregunta «¿qué debería tener una radio musical de servicio público?»:

Primera medida. Debería formar parte de un contrato-programa con obligaciones sobre las cuotas, los temas que deben tratarse, la relación como el público como de darse, etc. Ha sido un error, como la radio funcionaba se han centrado los esfuerzos en la televisión.

Segunda medida. No parece posible un solo formato de radio musical. Gaztea funciona, pero EITB Musika falla en el formato, aunque los contenidos sean de calidad.

Tercera medida. Falta educación musical. No hay elementos de educación en diferentes géneros y estilos fuera del jazz y algún contenido de música clásica. Este contenido se puede «pildorizar» para distribuir en el circuito digital.

\section{Conclusiones}

En este artículo hemos realizado una aproximación a la percepción de los oyentes de Gaztea Irratia desde la perspectiva del servicio público. Este enfoque nos sirve para comprender y obtener nuevos datos sobre el estado de la cuestión de un tema que tiene un enorme interés para instituciones públicas, academia y ciudadanía. 
En los últimos años, es patente la apuesta de EITB por la radio musical dirigida a la audiencia juvenil, intenciones que se han manifestado en textos legales y corporativos, los cuales son importantes para asegurar la salvaguarda de Gaztea. Sin embargo, los buenos resultados de audiencia tienen como marco las acusaciones de "comercialidad». Esta es la principal crítica que hacen los participantes de los focus group al contenido musical de la emisora. Al mismo tiempo, reconocen su papel en la divulgación del euskera y en el tono juvenil de las comunicaciones. Gaztea les parece una emisora cercana porque habla en un idioma que conocen, y estiman, de cosas que les interesan o les resultan cercanas.

Obviamente en esta investigación hemos trabajado con oyentes de Gaztea Irratia. No es de extrañar que los participantes también sean oyentes habituales tanto de radio como de música. Sin embargo, este no es el perfil típico de la audiencia juvenil. El dilema está en cómo mantener, ampliar y conectar a los oyentes cuando existe una amplia oferta de contenidos musicales y existe una desafección por la radio. La radio musical pública hace tiempo que superó el estadio teórico para innovar en la práctica, algo que ha sido aceptado por la población, como es el caso de Gaztea. "We should assume less and test more» (EBU, 2014b), indicaba un directivo en un informe de la EBU sobre audiencias jóvenes. Este debería ser el punto de partida para lograr la supervivencia y el éxito: ensayo-error sin miedo a fracasar.

\section{Referencias bibliográficas}

AIMC (Asociación para la Investigación de Medios de Comunicación). (2018). 21. ${ }^{a}$ encuesta Navegantes en la Red. Recuperado de https://www.aimc.es/otros-estudios-trabajos/ navegantes-la-red/

Aguiar, L., Martens, B. (2013). Digital Music Consumption on the Internet: Evidence from Clickstream Data. Recuperado de http://ftp.jrc.es/EURdoc/JRC79605.pdf

Amo, J.A. del (2014). Party \& borroka. Jóvenes, música(s) y conflicto(s) en Euskal Herria: transformaciones identitarias a comienzos del siglo xxI (tesis doctoral) Universidad del País Vasco-Euskal Herriko Unibertsitatea, Leioa.

Aramburu, J. (2018). Entrevista telefónica. 13/11/2018.

Barnard, S. (1989). On the Radio. Music radio in Britain. Philadelphia: Open University Press.

BBC Trust. (2015). BBC Trust Service Review Radio 1, 1Xtra, Radio 2, Radio 3, 6 Music and Asian Network. Recuperado de http://www.bbc.co.uk/bbctrust/news/press_ releases/2015/music_radio

Blumler, J. (2014). Entrevista personal. Leeds, 8/10/2014.

Bonini, T. (2014). The new role of radio and its public in the age of social network sites. First Monday, 19(6). Recuperado de http://firstmonday.org/article/view/4311/4093 
Bonet, M., Fernández-Quijada, D., y Ribes, X. (2011). The Changing Nature of Public Service Radio: en Case Study of iCat FM. Convergence: The International Journal of Research into New Media Technologies, 17(2), 177-192.

Bonet, M., y Sellas, T. (2016). L'àudio en Internet: de la radio en línea als projectes nadius. Recuperado de https://www.cac.cat/pfw_files/cma/IX_Ajuts_Audio_Internet_Sellas_ Bonet.pdf

Comisión Europea. (2009). Communication from the commission on the application of state aid rules to public service broadcasting (text with EEA relevance). Recuperado de http://ec.europa. eu/competition/state_aid/legislation/broadcasting_communication_en.pdf

CAC (Consell de l'Audiovisual de Catalunya). (2016). Informe en relació amb el compliment de las missions específiques del servei público de competència de la Generalitat de Catalunya. Any 2015. Recuperado de http://statics.ccma.cat/multimedia/ pdf/6/8/1474382557386.pdf

Consejería de Cultura, y EITB (Euskal Irrati Telebista). (2012). Contrato Programa con el Ente Público de Derecho Privado "Radio Televisión Vasca-Euskal Irrati Telebista" para el periodo 2012 y su anexo de concreción de compromisos al mismo». Recuperado de http://www. eitb.com/multimedia/corporativo/documentos/contrato-programa-2012.pdf

Costa Gálvez, L. (2013). Como lo oyes. La publicación de listados de reproducción de los programas temáticos musicales en la radio de titularidad pública en España. Trípodos, 33, 73-98.

Costa Gálvez, L. (2017). There's en star man waiting in the sky'. How does public radio approach under-the-radar-musicians in the United Kingdom and Spain? The Radio Journal, 15(1), 65-88.

Departamento de Cultura del Gobierno Vasco. (2006). Balance del contrato programa Periodo 2002-2005. Recuperado de http://www.parlamento.euskadi.net/irud/08/00/005153. pdf

Departamento de Cultura y Política Lingüística (2019). Promoción de la cultura. Música. Recuperado de http://www.euskadi.eus/musica-promocion-cultura/web01-a2musika/es/

Departamento de Presidencia; Consejería de Hacienda y Administración Pública, Consejería de Cultura, y EITB (Euskal Irrati Telebista). (2007). Contrato-programa con el ente público Radio Televisión vasca (EITB) para el periodo 2007-2010. Recuperado de http:// www.kultura.ejgv.euskadi.net/r46-kghz2/es/contenidos/informacion/eitb/es_eitb/ adjuntos/EITB_0710.pdf

EBU (European Broadcasting Union). (2014a). Vision 2020. Annexes 8. Experts group 2: distribution, technology \& audiences, Report \& Summary. Recuperado de http://www3.ebu. ch/files/live/sites/vision2020/files/app/annexe_8_EN.pdf

EBU (European Broadcasting Union). (2014b). Summary of interviews with members understanding young audiences. Recuperado de https://www.ebu.ch/publications/reports/ understanding-young-audiences

EBU (European Broadcasting Union). (2018). Audience Trends: Radio 2018. Recuperado de https://www.ebu.ch/publications/audience-trends-radio-2018 
EITB (Euskal Irrati Telebista). (2012d). Albiste testu bikainak (libro de estilo). Recuperado de http://www.eitb.com/multimedia/corporativo/documentos/albiste-testu-bikainakeuskaraz-eitb.pdf

EITB (Euskal Irrati Telebista). (2013b). Plan estratégico EITB 2013-2016. Recuperado de http://www.eitb.com/multimedia/corporativo/documentos/plan-estrategico-eitb2013-2016.pdf

EITB (Euskal Irrati Telebista). (2018). Más de medio millón de oyentes escuchan las radios de EiTB, según CIES. Recuperado de https://www.eitb.eus/es/radio/detalle/5617422/ mas-medio-millon-oyentes-escuchan-radios-eitb-cies/

Elordui, A. (2016). Challenges of Language Policy in Youth Media: Minority media and language policymakers converging in goals. ZER Revista de Estudios de Comunicación, 21(40), 161-176. doi: 10.1387/zer.15513

Euskampus (2014). Alumnado matriculado por centro universitario. Recuperado de http://www. ehu.eus/zenbakitan/es/node/29.html

Eusko Jauralitza/Gobierno Vasco (2018). 67 Euskal Soziometroa Hedabideak-EITB/Sociómetro Vasco 67 Medios de Comunicación-EITB. Recuperado de http://www.euskadi.eus/ contenidos/documentacion/sociometro_vasco_67/es_def/adjuntos/18sv67.pdf

EUSTAT (Euskal Estatistika Erakundea). (2011). Indicadores estructurales. Recuperado de http://www.eustat.eus/indic/indicadoresEstruc.html

Frith, S. (2002). Look! Hear! The Uneasy Relationship of Music and Television. Popular Music, 21(3), 277-290.

Gandarias, L. y Cardiel, G. (2018). Entrevista personal. Asua, 03/10/2018.

Garitaonandia, C. (1988). La radio en España (1923-1939). De altavoz musical a arma de propaganda. Bilbao: Servicio editorial de la Universidad del País Vasco.

Gazte Aukera (Observatorio Vasco de la Juventud). (2017). Estadísticas. Ocio, cultura $y$ deporte. Recuperado de http://www.gazteaukera.euskadi.eus/r58-7650x/es/estatistikak/ listaV1. apl idioma $=c \&$ tema $=193 \&$ ambito $=1$

Gendrau, L. (2012). Joves, medios de comunicación y consum cultural. Treballs de Sociolingüística Catalana, 22, 179-188.

Guimerà i Orts, J.À. (2014). Les Politiques de mitjans de comunicació durant els governs de Jordi Pujol: premsa, radio i televisió en el procés de reconstrucció nacional de Catalunya. Barcelona: Proa.

Guridi, M. (2018). Entrevista personal. Vitoria-Gasteiz, 08/10/2018.

Gutiérrez, M., Ribes, X., y Monclús, B. (2011). La audiencia juvenil y el acceso a la radio musical de antena convencional a través de Internet. Comunicación y Sociedad, XXIV(2), 305-331.

Hennion, A., y Meadel, C. (1986). Programming music: radio as mediator. Cultural Society, 1(1), 97-114.

Herrera Damas, S. (2003). Tipología de la participación de los oyentes en los programas de radio. Anàlisi, 30, 145-166. 
Hoyos, G. (2015). Cultura y televisión pública: ¿indefinición o desinterés? El caso de la RTVA y Canal Sur 2. Derecom, 19, 33-47.

Hoyos, G., y Costa Gálvez, L. (2017). Culture as pretext? Public Service Media and citizen engagement in times of crisis. Media and Communication / Mediji i komunikacije, 7, 50-67.

IFPI (International Federation of the Phonographic Industry). (2015). Informe sobre la música digital de la IFPI 2015. Recuperado de http://www.ifpi.org/downloads/DigitalMusic-Report-2015-Spanish.pdf

Jakubowicz, K. (2007). Qui d'autre que nous? La radiodiffusion de service public et la cultura au 21e siècle. En C. Nissen (coord.), Faire la differènce. La radiodiffusion de service public dans le paysage audiovisual européen (pp. 37-54). Eastleigh, Ginebra: John Libbey Publishing, EBU.

Jauert, P. (2012). The Soundscape Formerly Known As Radio?- A study in the transformations of production and use of public service radio, Conferencia presentada en el Ripe 2012, Sydney, 5-7 de septiembre.

Jiménez Iglesias, E. (2010). Talk show y audiencia: los procesos de recepción de un género de telerrealidad (tesis doctoral). Universidad del País Vasco/Euskal Herriko Unibertsitatea, Leioa.

Lamarca, J. (2018). Entrevista personal. Donostia-San Sebastián, 15/10/2018.

Landabidea Urresti, L. (2013). Belaunaldien telebistarekiko aisiazko harremanak: Bizkaiko lau adin-talderen kasu azterketa (tesis doctoral). Deustuko Unibertsitatea, Bilbao.

Larondo Urreta, A. (2016). El avance de las televisiones públicas autonómicas en el escenario convergente: análisis de experiencias periodísticas transmedia en EITB y CCMA. Comunicación y Sociedad/Communication \& Society, 29(4), 107-120.

López Vidales, N., Gómez Rubio, L., y Redondo García, M. (2014). La radio de las nuevas generaciones de jóvenes españoles: Hacia un consumo on line de música y entretenimiento. Zer, 19(37), 45-64.

Martí, J.M. (1990). Modelos de programación radiofónica. Barcelona: Feed-Back Ediciones.

Martín Matos, J.A. (2013). El rock de las noticias. la actualidad y sus canciones de la tradición anglosajona al caso vasco (tesis doctoral) Universidad del País Vasco-Euskal Herriko Unibertsitatea, Leioa.

Martínez-Costa, P., y Moreno Moreno, E. (2004). Programación radiofónica. Arte y técnica del diálogo entre la radio y su audiencia. Barcelona: Ariel.

Miguel de Bustos, J.C., y Casado del Río, M.A. (2016). Google, Apple, Facebook y Amazon. Emergencia de los GAFA y cambios en el sistema comunicativo global. Telos: Cuadernos de comunicación e innovación, 104, 38-48.

Min Baek, Y. (2015). Relationship Between Cultural Distance and Cross-Cultural Music Video Consumption on YouTube. Social Science Computer Review, 33(6), 730-748.

Negus, K. (2005). Los géneros musicales y la cultura de las multinacionales. Barcelona; Paidós Comunicación 164. 
Nylund Hagen, A. (2015). The Playlist Experience: Personal Playlists in Music Streaming Services. Popular Music and Society, 38(5), 625-645.

Pedrero Esteban, L.M. (2000). La radio musical en España. Historia y análisis. Madrid: IORTV.

Peñafiel, C. (2007). Los retos de la radio en el entorno multimedia. En C. Peñafiel (ed.), Transformaciones de la radio y la televisión en Europa (pp. 19-34). Bilbao: Universidad del País Vasco.

Saudrigas, X. (2009). L'ús del català en la música pop-rock (1987-1994). Treballs de sociolingüística catalana, 29, 57-75.

TNS (Taylor Nelson Sofres), y Spotify (2015). The new audio. Reaching the Spotify listener in Europe. Recuperado de https://www.spotify.com/es/brands/insights/the-new-audiotns-study/

Vanhaeght, A.S., y Donders, K. (2015). Interaction, Co-creation and Participation in PSM Literature, Policy and Strategy: A Comparative Case Study Analysis of Flanders, the Netherlands, France and the UK. MedijskeStudije - Media Studies, 6(12), 46-6.

Wall, T. y Dubber, A. (2009). Specialist music fans online: implications for public service broadcasting. Listener online engagement with BBC Radio programming. Recuperado de: http:// www.bbc.co.uk/blogs/legacy/knowledgeexchange/birmingham.pdf

Zallo, R. (2018a). Desajuste y retraso de nuestro sistema cultural-comunicativo en el marco digital: retos para una identidad vasco-navarra en construcción, Eusko Ikaskuntza Kongresua. Pamplona 26/10/2018.

Zallo, R. (2018b). Entrevista personal. Leioa, 28/10/2018. 